\title{
Recruitment of Additional Corticospinal Pathways in the Human Brain with State-Dependent Paired Associative Stimulation
}

\author{
Dominic Kraus, ${ }^{1}$ Georgios Naros, ${ }^{1}$ Robert Guggenberger, ${ }^{1}$ Maria Teresa Leão, ${ }^{1}$ Ulf Ziemann, ${ }^{2}$ \\ and $\oplus^{-A}$ Alireza Gharabaghi ${ }^{1}$ \\ ${ }^{1}$ Division of Functional and Restorative Neurosurgery, and Centre for Integrative Neuroscience, and ${ }^{2}$ Department of Neurology and Stroke, and Hertie \\ Institute for Clinical Brain Research, Eberhard Karls University Tuebingen, 72076
}

Standard brain stimulation protocols modify human motor cortex excitability by modulating the gain of the activated corticospinal pathways. However, the restoration of motor function following lesions of the corticospinal tract requires also the recruitment of additional neurons to increase the net corticospinal output. For this purpose, we investigated a novel protocol based on brain statedependent paired associative stimulation.

Motor imagery (MI)-related electroencephalography was recorded in healthy males and females for brain state-dependent control of both cortical and peripheral stimulation in a brain-machine interface environment. State-dependency was investigated with concurrent, delayed, and independent stimulation relative to the MI task. Specifically, sensorimotor event-related desynchronization (ERD) in the $\beta$-band $(16-22 \mathrm{~Hz})$ triggered peripheral stimulation through passive hand opening by a robotic orthosis and transcranial magnetic stimulation to the respective cortical motor representation, either synchronously or subsequently. These MI-related paradigms were compared with paired cortical and peripheral input applied independent of the brain state. Cortical stimulation resulted in a significant increase in corticospinal excitability only when applied brain state-dependently and synchronously to peripheral input. These gains were resistant to a depotentiation task, revealed a nonlinear evolution of plasticity, and were mediated via the recruitment of additional corticospinal neurons rather than via synchronization of neuronal firing. Recruitment of additional corticospinal pathways may be achieved when cortical and peripheral inputs are applied concurrently, and during $\beta$-ERD. These findings resemble a gating mechanism and are potentially important for developing closed-loop brain stimulation for the treatment of hand paralysis following lesions of the corticospinal tract.

Key words: corticospinal pathways; event-related desynchronization; motor imagery; paired associative stimulation; state-dependent stimulation; transcranial magnetic stimulation

\section{Significance Statement}

The activity state of the motor system influences the excitability of corticospinal pathways to external input. State-dependent interventions harness this property to increase the connectivity between motor cortex and muscles. These stimulation protocols modulate the gain of the activated pathways, but not the overall corticospinal recruitment. In this study, a brain-machine interface paired peripheral stimulation through passive hand opening with transcranial magnetic stimulation to the respective cortical motor representation during volitional $\beta$-band desynchronization. Cortical stimulation resulted in the recruitment of additional corticospinal pathways, but only when applied brain state-dependently and synchronously to peripheral input. These effects resemble a gating mechanism and may be important for the restoration of motor function following lesions of the corticospinal tract.

\section{Introduction}

In animal models, activity-dependent electrical stimulation may result in changes in connectivity and synaptic efficacy. This is accomplished by stimulating a cortical area either in conjunction with activity in another cortical area (Jackson et al., 2006) or with muscle activity (Lucas and Fetz, 2013). Similar paired associative stimulation (PAS) protocols have been investigated in human 
subjects as well. Specifically, single-pulse transcranial magnetic stimulation (TMS) was applied together with peripheral electrical stimulation following specific timing rules to induce plastic changes of corticospinal excitability (CSE; Stefan et al., 2000). Subjects were at rest while these initial studies were conducted.

A further step in understanding the brain state-dependent effect on CSE was presented by pairing two cortical stimuli in a time-dependent manner. Bihemispheric stimulation of homologous motor areas showed long-term potentiation (LTP)like increases in CSE indexed by enhanced motor-evoked potential (MEP) amplitudes following TMS of the primary motor cortex (Koganemaru et al., 2009; Rizzo et al., 2009). Similar observations were made when the motor cortex stimuli were preceded by a stimulus over the supplementary motor area (SMAproper; Arai et al., 2011). Long-term depression (LTD)-like results could also be achieved by pairing ventral premotor with primary motor cortex stimulation (Buch et al., 2011). These changes turned into LTP-like results when a grasping task was introduced, indicating that the same stimulation paradigm could switch from LTD-like to LTP-like effects depending on the activity state of the motor system (Davare et al., 2009; Buch et al., 2011). Finally, LTP-like increases in CSE were shown by timing a peripheral stimulus to the movement-related brain activity in the movement execution phase of a motor imagery task (MrachaczKersting et al., 2012; Xu et al., 2014).

In a next step, movement-dependent TMS was applied with respect to the electromyography (EMG) onset of voluntary muscle contraction (Bütefisch et al., 2004; Thabit et al., 2010; Edwardson et al., 2013). Because this approach showed a broader time window for plasticity induction than traditional PAS protocols, activity-dependent interventions are potentially more suitable for clinical application (Edwardson et al., 2013; Gharabaghi, 2015). However, these protocols depended on voluntary muscle control. They are, therefore, not applicable to patients with severe lesions of the corticospinal tract such as stroke patients with hand paralysis for whom novel plasticity-inducing interventions are specifically required to reestablish an effective connectivity between cortex and muscles.

Brain-machine interfaces (BMIs) may offer a method to overcome this limitation by providing both brain state-dependent and movement-related stimulation. These devices facilitate volitional control of passive hand opening by a robotic orthosis, e.g., via motor imagery (MI) of the respective movement and contingent to event-related desynchronization (ERD). Such statedependent proprioceptive input was recently shown to activate oscillatory networks that resemble the cortical activation during overt movement (Bauer et al., 2015; Vukelić and Gharabaghi, 2015a). However, refined TMS mapping techniques (Kraus and Gharabaghi, 2015, 2016; Kraus et al., 2015) revealed distributed modulations of CSE; the motor hand knob area in particular, which controlled the BMI by MI-related ERD, showed a CSE decrease at the plateau of the stimulus-response curve, suggesting a reduction of net corticospinal output (Kraus et al., 2016b).

In this context, we hypothesized that a novel protocol integrating brain state-dependent cortical stimulation (Kraus et al., 2016a) into a BMI intervention would invert this reduction of net

The authors declare no competing financial interests.

Correspondence should be addressed to Alireza Gharabaghi, Division of Functional and Restorative Neurosurgery, Eberhard Karls University Tuebingen, Otfried-Mueller-Str. 45, 72076 Tuebingen, Germany. E-mail: alireza.gharabaghi@uni-tuebingen.de.

DOI:10.1523/JNEUROSCI.2893-17.2017

Copyright $\odot 2018$ the authors $\quad 0270-6474 / 18 / 381397-12 \$ 15.00 / 0$ corticospinal output; specifically, state-dependency was investigated with concurrent, delayed, and independent stimulation relative to the MI task to control for priming effects, task-related elevated attention, or mere pairing of cortical and peripheral stimulation. Furthermore, we intended to detect robust increases of CSE resistant to a depotentiation task because previous PAS protocols indicate an association between the induced plasticity and the voluntary motor output in both injured and healthy subjects (Taylor and Martin, 2009; Bunday and Perez, 2012).

The present study revealed that cortical stimulation results in a significant and robust increase of net corticospinal output mediated via the recruitment of additional neuronal pools when applied during $\beta$-ERD and synchronously to proprioceptive input.

\section{Materials and Methods}

\section{Subjects}

A total of 27 healthy subjects (mean age, $25.3 \pm 2.7$ years, range $19-32$ years; 17 male) without contraindications to TMS (Rossi et al., 2009) and without a history of neurological or psychiatric disease participated in this study, which consisted of three experiments in a parallel group design. Two brain state-dependent stimulation experiments and one nonspecific brain stimulation experiment were performed with motor cortical stimulation by TMS and peripheral stimulation by a robotic hand orthosis; brain state-dependent TMS was applied either concurrent (i.e., synchronous) or subsequent (i.e., delayed) to motor imagery-related ERD-controlled orthosis movement: Experiment 1: synchronous stimulation; Experiment 2: delayed stimulation; and Experiment 3: nonspecific stimulation. The Edinburgh handedness inventory (Oldfield, 1971) confirmed right-handedness. The study was approved by the local ethics committee and all subjects gave written informed consent before participation. If subjects participated in more than one experiment, the sessions were separated by at least $5 \mathrm{~d}$ to avoid carryover effects. The number of subjects in each experiment was as follows: Experiment 1: 13 subjects; Experiment 2: 12 subjects; Experiment 3: 10 subjects. One subject participated in Experiments 1-3, two subjects in Experiments 1-2, three subjects in Experiments1/3, and five subjects in Experiments 2/3. The experimental setup has already been described by our group and is cited here (see Experimental conditions) when performed in the same way (Kraus et al., 2016a,b):

\section{Recordings}

Electromyography. We used Ag/AgCI AmbuNeuroline 720 wet gel surface electrodes (Ambu) to record EMG activity from the left extensor digitorum communis (EDC) muscle during the intervention. We placed two electrodes on the muscle belly $2 \mathrm{~cm}$ apart from each other. After filtering between $0.16 \mathrm{~Hz}$ and $1 \mathrm{kHz}$, EMG was recorded with $5 \mathrm{kHz}$ sampling rate and downsampled to $1 \mathrm{kHz}$ by the BrainAmp amplifier. To determine plastic changes (see below), we applied the integrated 6-channel EMG device of the eXimia Navigated Brain Stimulation (NBS) system (Nexstim) with $3 \mathrm{kHz}$ sampling rate and bandpass filter of $10-500 \mathrm{~Hz}$ before and after the intervention.

Electroencephalography. Throughout the experiment, $\mathrm{Ag} / \mathrm{AgCl}$ electrodes and BrainVision software with DC amplifiers and an antialiasing filter (BrainAmp, Brain Products $\mathrm{GmbH}$ ) were used to record electroencephalography (EEG) signals in a 32-channel setup that complied with the international 10-20 system (Fp1, Fp2, F3, Fz, F4, FT7, FC5, FC3, FC1, FC2, FC4, FC6, FT8, C5, C3, C1, Cz, C2, C4, C6, TP7, CP5, CP3, CP1, $\mathrm{CPz}, \mathrm{CP} 2, \mathrm{CP} 4, \mathrm{CP} 6, \mathrm{TP} 8, \mathrm{P} 3, \mathrm{P} 4, \mathrm{POz}$ with $\mathrm{FCz}$ as reference). Impedances at all electrodes were set $<10 \mathrm{k} \Omega$ for each experiment. Following digitization at $1 \mathrm{kHz}$ rate, high-pass filtering with $0.16 \mathrm{~Hz}$ and low-pass filtering with $1000 \mathrm{~Hz}$, the EEG signals were transferred for online analysis to BCI2000 software, where they were later stored off-line (Schalk et al., 2004). Because ambient noise could affect electrophysiological recordings, we made every effort to remove its potential sources from the experimental environment by turning off mobile phones, unplugging superfluous power supplies and computers, etc. The effect of this procedure on, for example, the $50 \mathrm{~Hz}$ line noise, was verified online. 
a
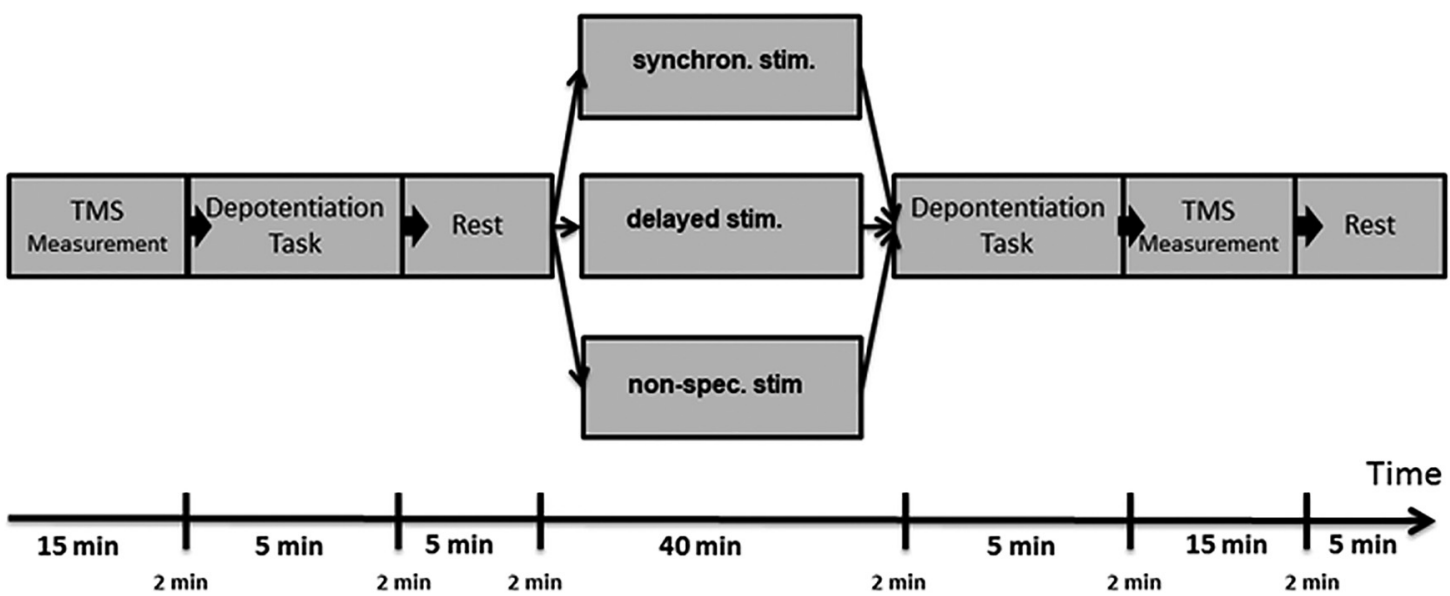

b
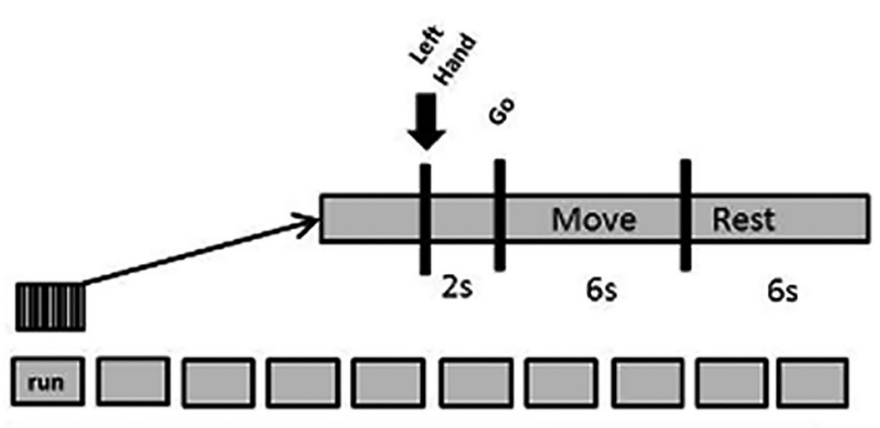

11 trials

15 runs (2.5min each)

\section{1 session}

$\sim 40 \mathrm{~min}$

C

synchron. stim.

Cortical stimulation

ERD

Peripheral stimulation
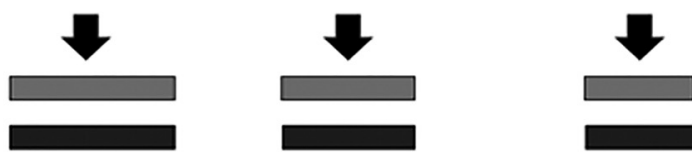

delayed stim.

Cortical stimulation

ERD

Peripheral stimulation
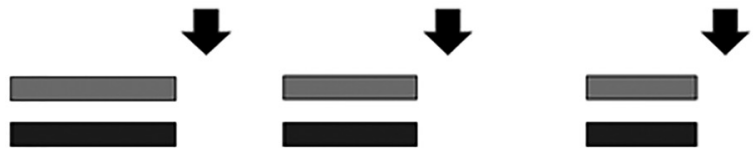

non-spec. stim.

Cortical stimulation
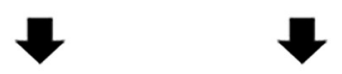

Peripheral stimulation

Figure 1. $\boldsymbol{a}$, Schematic illustration of experimental design. $\boldsymbol{b}$, Timeline of the intervention. $\boldsymbol{c}$, The pictogram illustrates details of the experimental conditions: cortical stimulation concurrent to ERD-triggered peripheral stimulation (synchronous stimulation); subsequent to ERD-triggered peripheral stimulation (delayed stimulation); and concurrent to peripheral stimulation but independent of the brain state (nonspecific stimulation).

TMS protocol

We used a navigated TMS stimulator (eXimia, Nexstim) with a biphasic current waveform connected to a figure-8 eXimia Focal Bipulse Coil (5 $\mathrm{cm}$ mean winding diameter) to determine MEP stimulus-response curves (SRCs) before and after the intervention, as well as during the intervention (Fig. 1). Before the experiment, a 3-tesla Siemens TIM Trio MRI system (Siemens AG) was used to obtain anatomical T1-weighted magnetic resonance imaging sequences for each participant. Images were 
loaded into the eXimia NBS system for coregistration with the participant's head. Subjects were seated in a comfortable reclining chair. The representation of the left EDC in the right M1 was determined for each subject before the onset of the first experiment. As initial intensity, we used $40 \%$ of maximum stimulator output and the anatomically defined "hand knob" of M1. Whenever the initial stimulator output did not suffice to elicit MEPs, we increased output in steps of 5\%. We ensured that the orientation of the coil remained perpendicular to the central sulcus and defined the coil site that consistently elicited the largest MEPs as our stimulation site. Having determined this "hotspot", we varied the orientation of the coil in steps of $\sim 10^{\circ}$ around the original orientation to ascertain which orientation elicited the largest MEP at this site. The optimal coil orientation and location remained constant throughout the session. We then determined the resting motor threshold (RMT) by the relative frequency method, i.e., by detecting the minimum stimulus intensity (closest $2 \%$ of maximum stimulator output) that resulted in MEPs $>50 \mu \mathrm{V}$ in the peak-to-peak amplitude in at least 5 of 10 consecutive trials (Ziemann et al., 1996; Groppa et al., 2012). We calculated the RMT and the MEP stimulus-response curve to determine corticospinal excitability at baseline (before intervention) and after the intervention. The estimated electrical field of the NBS system at the hotspot in a depth of $\sim 22 \mathrm{~mm}$ (Danner et al., 2008, 2012) was then used to determine the intensities for the MEP stimulus-response curve. The initial intensity was set at $60 \%$ RMT and was increased in steps of $10 \mathrm{~V} / \mathrm{m}$. Ten MEPs were recorded for each intensity step. Subjects were requested to keep their muscles relaxed for the duration of all TMS measurements. We inspected the EMG data during off-line analysis, discarding any trials containing muscle pre-activation. Less than $1 \%$ of all trials were rejected due to contamination by muscle activity.

Depotentiation of fragile stimulation effects. To identify any stimulation effects that persisted despite voluntary muscle contraction, participants were asked to perform a depotentiation task (Todd et al., 2009; Goldsworthy et al., 2015). In this task, which consisted of a bar drifting rhythmically up and down on a computer screen, subjects were requested to match the bar with a ball on the screen. This ball was controlled by a hand orthosis (AMADEO, Tyromotion) attached to the subject's hand. Subjects were instructed to extend the fingers in the hand orthosis to initiate an upward movement of the ball and to flex the fingers to move the ball downward on the screen accordingly. When matched with the moving bar, the ball on the screen turned from red to green. This depotentiation task, which lasted for $5 \mathrm{~min}$, was performed twice during the experiment (Fig. 1A): (1) After the first TMS measurement to rule out potential effects of the TMS measurements per se (Todd et al., 2009) because 150 stimuli had been shown previously to induce transient changes of corticospinal excitability (Touge et al., 2001), and (2) following the intervention to identify robust changes of corticospinal excitability (Goldsworthy et al., 2015).

\section{Experimental conditions}

The experiment is outlined in Figure $1 B$. It comprised two brain statedependent interventions (Experiments 1-2) and one intervention that was independent of the brain state (Experiment 3). Each intervention lasted for $\sim 40 \mathrm{~min}$ and consisted of 15 runs. Each run took $\sim 2.5 \mathrm{~min}$ and contained 11 trials. In Experiments 1 and 2, a preparation phase of $2 \mathrm{~s}$ marked the onset of each trial. This was followed by a 6 s motor imagery ("move") phase and a $6 \mathrm{~s}$ rest phase. The auditory cues "left hand" and "go", presented by a recorded female voice, marked the onset of the preparation and imagery phases. Subjects performed kinesthetic motor imagery task during the motor imagery phase. They were instructed to imagine and sense opening their left hand from a first-person perspective without actually moving it. To prevent active movement, the hand was attached to a hand orthosis throughout the experiment (AMADEO, Tyromotion). The motor imagery feedback consisted of contingent peripheral stimulation delivered by passive opening of the left hand by the robotic hand orthosis. With an application for rehabilitation purposes in mind, we chose passive opening of the hand over a peripheral electrical stimulus to the median nerve, as used in traditional PAS protocols. This mimicked a peripheral stimulation as applied in conventional physiotherapy. In the rest phases, the subjects were asked to count backwards from 10 without paying attention to their left hand.

Contingency between motor imagery and robotic opening of the hand was established via ERD. ERD detection was confined to electrodes FC4, C4, and CP4 over the right sensorimotor area (McFarland et al., 2000). Once ERD disappeared, robotic movement, i.e., peripheral stimulation, ceased. We used a linear classifier of nine features, consisting of three 2 $\mathrm{Hz}$ frequency bins $(16-22 \mathrm{~Hz}$ ) and three channels (FC4, C4, and CP4), to detect decreases in sensorimotor rhythm power in the $\beta$-band. An autoregressive model, with a model order of 16 and based on the Burg algorithm, was used to estimate frequency power (McFarland and Wolpaw, 2008). Five consecutive $40 \mathrm{~ms}$ epochs had to be classified as ERD-positive before stimulation could be initiated. This ensured that peripheral stimulation occurred during prolonged sessions of ERD only. The subjects were instructed to perform motor imagery, i.e., sustained or reestablished ERD, throughout the $6 \mathrm{~s}$ move phase to reinitiate the robotic hand movement whenever it stopped. At the end of the move phase, the robotic orthosis closed the hand again and returned to the starting position.

We selected these three electrodes (FC4, C4, and CP4) to cover premotor, primary motor, and somatosensory areas, all of which are known to be involved in functional restoration following stroke (Naros and Gharabaghi, 2015; Gharabaghi, 2016; Belardinelli et al., 2017). The spectral power range for feedback $(16-22 \mathrm{~Hz})$ was chosen on the basis of our previous findings. These had indicated that the effective corticospinal connectivity was mediated in this frequency band (Kraus et al., 2016b; Raco et al., 2016; Royter and Gharabaghi, 2016; Darvishi et al., 2017), which also correlated with subsequent motor gains (Naros et al., 2016). Notably, movement-related beta power desynchronization in the human sensorimotor cortex was shown to be a highly reliable biomarker across sessions (Espenhahn et al., 2017). Moreover, movement-related desynchronization in the ipsilesional sensorimotor cortex was compromised in stroke patients compared with healthy controls, i.e., the more severe the patient's motor impairment, the less $\beta$-band desynchronization (Rossiter et al., 2014). To facilitate the (re)leaning of $\beta$-band modulation under these circumstances and to avoid e.g., artifactual control (Gharabaghi et al., 2014b), methodological adjustments of the BMI have to be made (Bauer and Gharabaghi, 2015a,b, 2017). Even though other biomarkers might provide higher classification accuracy (Gomez-Rodriguez et al., 2011; Gharabaghi, 2016), $\beta$-band desynchronization would provide a (patho)physiologically inspired and (re)learnable intervention target (Romei et al., 2016). We therefore applied the same frequency-range and setup here as in our previous BMI studies with healthy subjects and stroke patients (Gharabaghi et al., 2014a; Vukelić et al., 2014; Brauchle et al., 2015; Vukelić and Gharabaghi, 2015a,b; Bauer et al., 2016a,b; Kraus et al., 2016a,b).

Before the experiment, a desynchronization task, consisting of three motor imagery training runs without robotic stimulation, was performed for calibration to account for each subject's ability for desynchronization. Following this calibration session, an individual desynchronization threshold, described in detail previously (Naros and Gharabaghi, 2015), was implemented for the intervention. This threshold balanced challenge and motivation of the participant and preserved the specificity of the feedback, i.e., stimulation was not provided until subjects attained consistent ERD. Robotic hand opening (peripheral stimulation) did not occur whenever the threshold was not met due to event-related synchronization (ERS) or when the ERD was not consistent, i.e., not long and/or not strong enough. The ERD threshold ensured that each subject received the same task-related demand and that this remained constant throughout the intervention. In Experiment 3, the robot opened the hand during the move phase independent of the brain state. The experimental conditions are illustrated in Figure $1 C$.

Experiment 1: cortical stimulation concurrently to ERD-triggered peripheral stimulation (synchronous stimulation). A biphasic single TMS pulse was used to stimulate the EDC hotspot of the right M1 with 110\% RMT. Whenever ERD was detected in the $\beta$-band $(16-22 \mathrm{~Hz}$ ) during the motor imagery phase, the BCI2000 software triggered cortical stimulation concurrent with peripheral stimulation (Gharabaghi et al., 2014a). If ERD was sustained or reestablished after the first stimulus, more than one 
TMS pulse was applied during the motor imagery phase. The minimum interstimulus interval was set at $500 \mathrm{~ms}$. We discarded the first $50 \mathrm{~ms}$ after each pulse and used a modified Burg algorithm for segmented data in the online analysis to interpolate the gap (Walter et al., 2012). This ensured that the EEG signal in the $\beta$-range was not contaminated by the TMS artifact.

Experiment 2: cortical stimulation subsequent to ERD-triggered peripheral stimulation (delayed stimulation). The procedure was identical to that in Experiment 1. The timing of cortical stimulation was, however, $80 \mathrm{~ms}$ after offset of the robotic hand opening, i.e., proprioceptive stimulation, based on a PAS rationale and in accordance with previous research which suggests a peak of the proprioceptive-related evoked potentials at a latency of $\sim 80-90 \mathrm{~ms}$ (Bötzel et al., 1997; Seiss et al., 2002).

Using this delayed approach, cortical stimulation was applied during the MI task to ensure that comparable levels of cognitive demand and vigilance were available in Experiments 1 and 2, but at a different brain state than in Experiment 1, i.e., whenever the predefined ERD level was not sustained due to ERS or insufficient ERD. The fact that excitability probed by TMS was elevated up to $200 \mathrm{~ms}$ after movement offset (Chen et al., 1998) suggests that the peripheral excitability states in Experiments 1 and 2 were similar at the time of cortical input. Experiment 2 therefore enabled us to investigate whether applying cortical stimulation during the MI task leads per se to plastic changes independent of the brain state of sustained $\beta$-ERD as achieved in Experiment 1.

Experiment 3: cortical stimulation concurrently to peripheral stimulation but independent of the brain state (nonspecific stimulation). In this experiment, neither peripheral nor cortical stimulation were triggered by ERD. Here, the sequence of cortical stimulation pulses (a replay of the recording in Experiment 1) was identical to that of Experiment 1. The same pattern of cortical stimulation was thus applied in Experiment 3 as in Experiment 1, but independent of the ongoing brain activity. In Experiment 3 , subjects were not required to perform the motor imagery task but were instructed to maintain muscle relaxation throughout the intervention while the robotic hand orthosis opened the hand during the move phase. This experiment enabled us to investigate whether synchronous cortical and peripheral stimulation would in itself lead to plastic changes independent of the brain state of sustained $\beta$-ERD.

Data analysis

MATLAB R2010b (MathWorks) with custom built code and SPSS V21 (IBM) were used to analyze the data.

Resting motor threshold. A repeated-measures ANOVA (rmANOVA) was performed for changes in RMT for the within-subject effect of Time (pre-, post-) and the between-subject effect of experiment (Experiments1-3). a

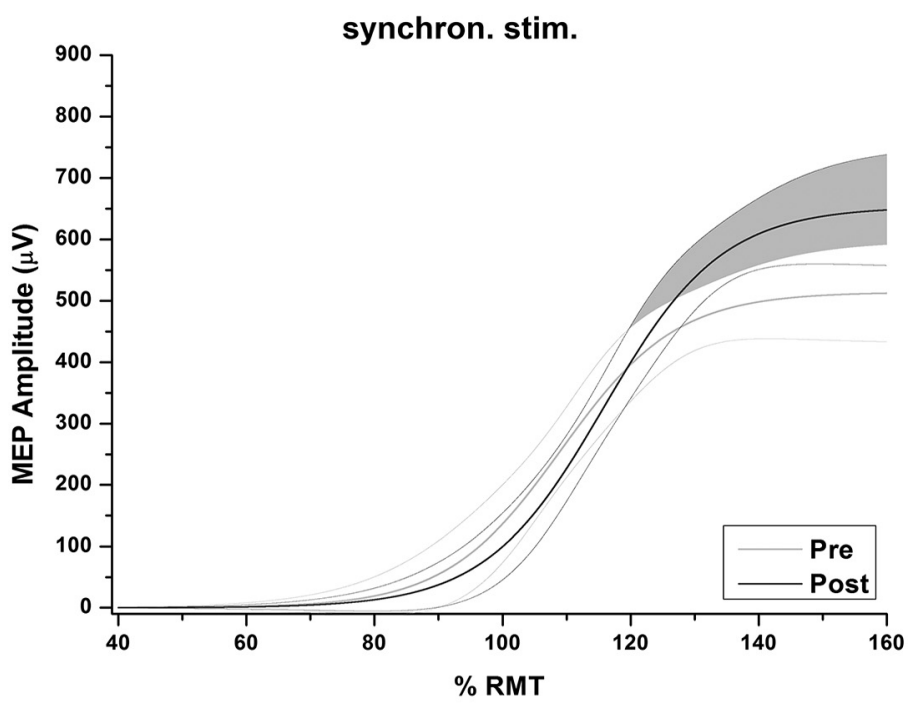

b

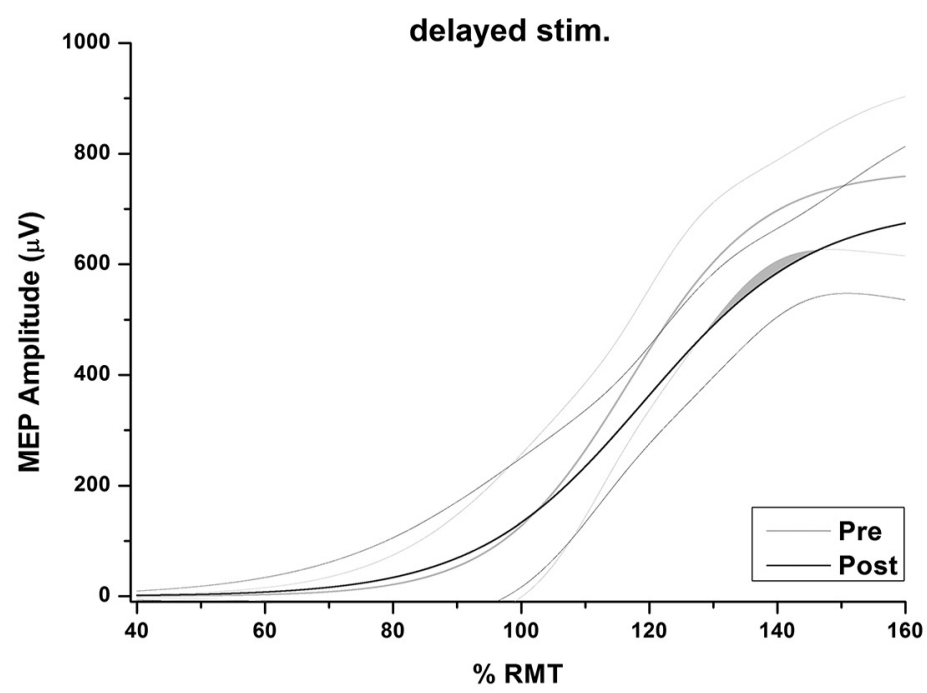

C

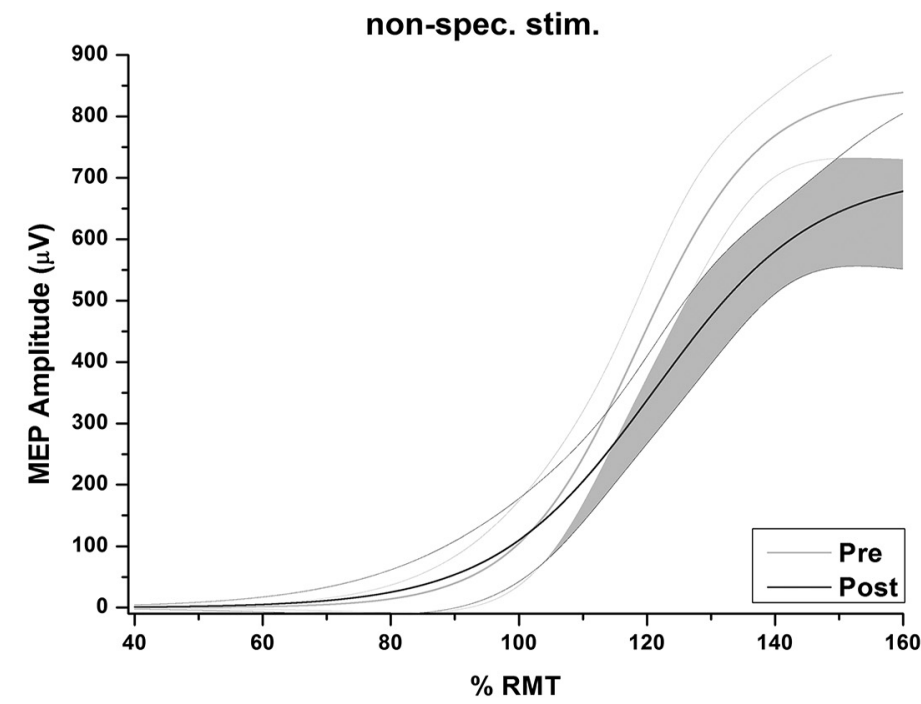

Figure 2. Peak to-peak MEP curve. Boltzmann fit (lines) of the mean peak to-peak MEP stimulus-response curve (in $\mu \mathrm{V}$ ) for pre-intervention (gray) and post-intervention (black) for synchronous (a), delayed (b), and nonspecific (c) stimulation, respectively. Each Boltzmann curve is paralleled by thin lines running above/below it and indicating the respective $95 \%$ confidence intervals. Shaded areas indicate significant differences between pre- versus post-curves. 
a

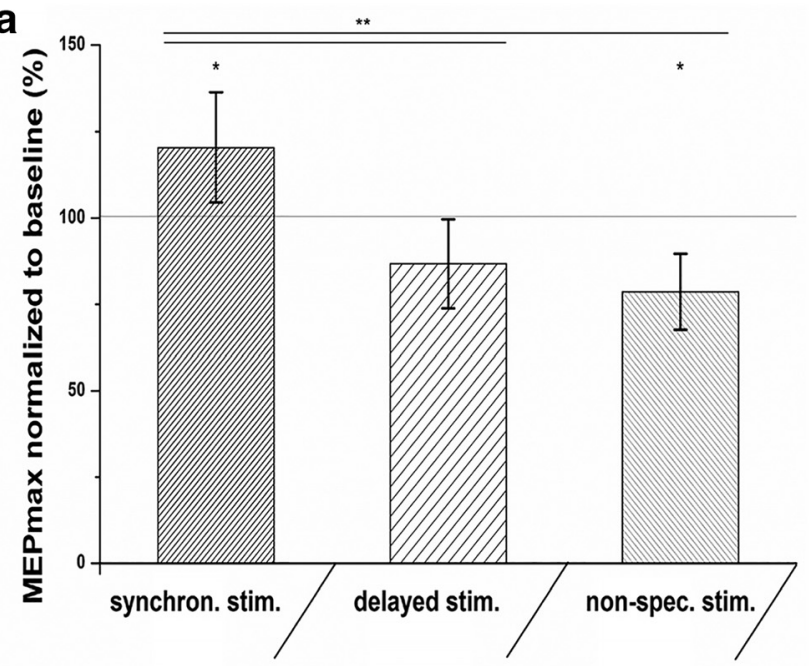

b

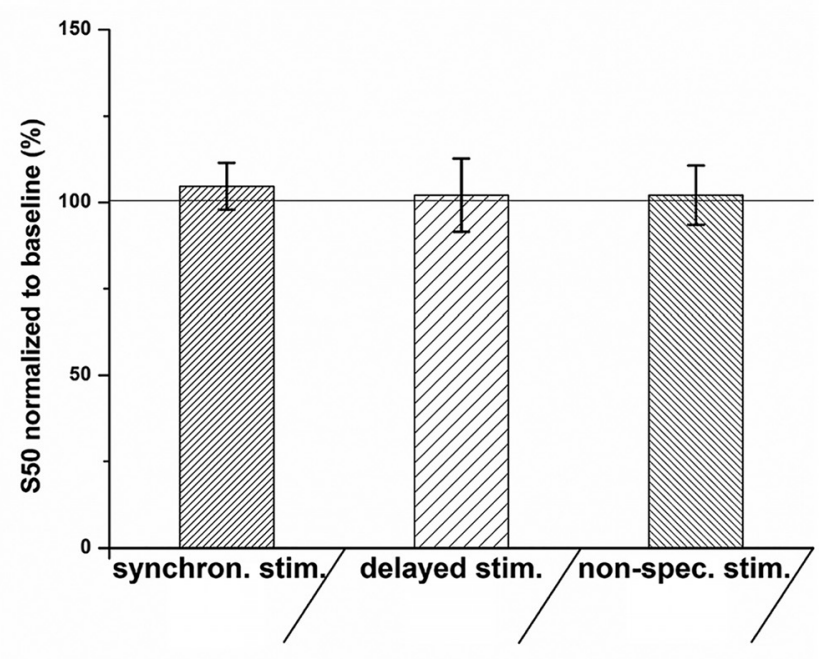

C

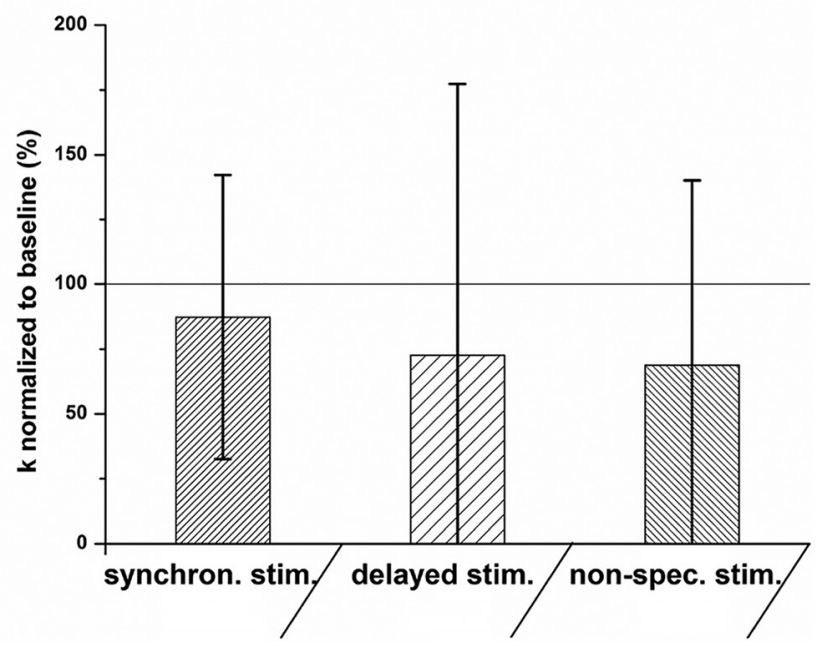

Figure 3. Boltzmann parameters of the peak-to-peak MEP curve. Means of (a) MEP $P_{\text {max }}$ (b) S50, and (c) slope $k$ post-intervention normalized to baseline (in percentage). Error bars indicate $95 \%$ confidence intervals. * Significant differences pre- versus post-intervention ( $p<$ 0.0017). ${ }^{* *}$ Significant differences between interventions $(p<0.0017)$.
Changes in MEP amplitude and area under the MEP curve. rmANOVA with time and intensity as within-subject effect and experiment as between-subject effect was performed on the binned data (bins: 71-90\%, 91-110\%, 111-130\%, and 131-160\% RMT) for MEP peak-to-peak amplitude and MEP area. When violation of sphericity was observed, a Greenhouse-Geisser correction was performed. Post hoc testing was performed as described below for the parameters of the SRC.

We fitted a three-parameter Boltzmann sigmoidal function to the preintervention and postintervention MEP SRC of all subjects. Peak-topeak amplitude was calculated using Equation 1 (Devanne et al., 1997; Houdayer et al., 2008; Möller et al., 2009) and the area under the MEP curve was derived from Equation 2. A Huber weighted least-squares method, which compensated for outliers and heteroscedasticity, was used to perform a robust fit, i.e., the further it moved away from the curve at each fitting iteration step, the further the response decreased linearly in weight (Huber and Winkler, 1981).

$$
\begin{gathered}
\operatorname{MEP}(\mathrm{S})=\mathrm{MEP}_{\text {max }} /(1+\exp (\mathrm{k}(\mathrm{S} 50-\mathrm{S}))) \\
\mathrm{MEP}_{\text {Area }}(\mathrm{S})=\mathrm{MEP}_{\text {max area }} /\left(1+\exp \left(\mathrm{m}\left(\mathrm{S}_{\text {area }} 50-\mathrm{S}\right)\right)\right)
\end{gathered}
$$

In Equations 1 and 2, $\operatorname{MEP}(S)$ represents the mean peak-to-peak MEP and the MEP Area $(S)$ stands for the mean area under the MEP curve elicited by a stimulus $S$ normalized to the RMT stimulation intensity. The saturation amplitudes of the peak-to-peak MEP amplitude and the MEP area are represented by $\mathrm{MEP}_{\max }$ and $\mathrm{MEP}_{\max \text { area }}$; they reflect the net corticospinal output and the recruitment of additional neuronal pools at the saturation level, where excitatory and inhibitory networks are balanced. $S 50$ and $S_{\text {area }} 50$ stand for the stimulation intensity required to gain $50 \%$ of the maximum response, whereas $k$ and $m$ are the slope parameters of $\operatorname{MEP}(S)$ and the MEP Area( $S)$, respectively, representing the gain of the activated corticospinal pathways (Devanne et al., 1997) or transsynaptic excitability (Ridding and Rothwell, 1997).

This resulted in one mean SRC for all subjects under the pre- and post-conditions. We calculated a $95 \%$ confidence for each curve parameter, as well as for the actual curves. We then calculated the $95 \%$ confidence interval of the differences between the means of the preintervention and postintervention curve parameters. This resulted in a confidence interval for the change between pre-condition and postcondition similar to a paired-sample $t$ test. The method described by Altman and Bland (2011) was used to calculate $p$ values for the differences in $\mathrm{MEP}_{\max }, \mathrm{MEP}_{\text {max area }}, S 50, S_{\text {area }} 50, k$, and $\mathrm{m}$. These were then Bonferroni-corrected for multiple comparisons $(\alpha=0.004)$.

Differences in EMG level and stimulation dose. Differences in background EMG level, duration of peripheral stimulation and number of cortical stimuli during the motor imagery phase were analyzed using multiple one-way rmANOVAs with the between-subject effect of intervention and within-subject variables $E M G$, duration, and number of stimuli. To clarify whether these differences were responsible for the observed plastic changes, we performed a multiple partial correlation for each experiment with the relative changes in the individual $\mathrm{MEP}_{\max }$ values using EMG, duration, and number of stimuli.

\section{Results}

The SRC of MEP amplitude (Fig. 2) and MEP area (see Fig. 4) showed significant changes after the intervention compared with baseline, with increases for Experiment 1 (synchronous stimulation) and decreases for Experiment 2 (delayed stimulation) and Experiment 3 (nonspecific stimulation). The Boltzmann parameters for MEP amplitude (Fig. 3) and MEP area (see Fig. 5) revealed significant changes of $\mathrm{MEP}_{\max }$ and $\mathrm{MEP}_{\text {max area }}$, but not for $S 50, S_{\text {area }} 50, m$, and $k$.

For the MEP peak-to-peak amplitude, rmANOVA revealed main effects of intensity $\left(F_{(1.771,56.678)}=111.938 ; p<0.001\right)$ and intervention $\left(F_{(2,32)}=3.356 ; p=0.048\right)$, and interactions of time $\times$ intervention $\left(F_{(2,32)}=4.265 ; p=0.023\right)$ and of time $\times$ intensity $\times$ intervention $\left(F_{(4.592,73.467)}=3.311 ; p=0.011\right)$; the 
results for the SRC are shown in Figure 2 and changes of Boltzmann parameters of the MEP amplitude are depicted in Figure 3.

For the MEP area, rmANOVA revealed main effects of intervention $\left(F_{(2,32)}=4.529\right.$; $p=0.019)$ and intensity $\left(F_{(1.843,58.965)}=\right.$ 115.663; $p<0.001)$, and interactions of time $\times$ intervention $\left(F_{(2,32)}=3.454 ; p=\right.$ $0.044)$, and of time $X$ intensity $X$ intervention $\left.\left(F_{(4.211,67.38}\right)=2.451 ; p=0.052\right)$; the results for the SRC of the MEP area are depicted in Figure 4 and those for the changes in MEP area parameters are summarized in Figure 5.

A significant main effect of time was found for the RMT $\left(F_{(1,32)}=5.126 ; p=\right.$ 0.03 ), but not for the interaction of time $X$ intervention. A post hoc paired-sample $t$ test did not reveal a significant RMT change in any of the experiments.

The different conditions revealed these specific findings:

Experiment 1: synchronous stimulation We found a significant $20.4 \%$ increase in $\mathrm{MEP}_{\max }(p<0.0001$; Figs. $2 a, 3 a)$, and a significant $29.2 \%$ increase in $\mathrm{MEP}_{\text {max area }}$ compared with baseline $(p<0.0001$; Figs. $4 a, 5 a)$. These increases in $\mathrm{MEP}_{\max }$ and $\mathrm{MEP}_{\text {max area }}$ differed significantly from those in Experiments 2 and 3 (all $p$ values <0.0006), and survived the depotentiation task performed immediately after the intervention (Todd et al., 2009; Goldsworthy et al., 2015).

Experiment 2: delayed stimulation

This intervention led to a decrease in $\mathrm{MEP}_{\max }$ by $13.3 \%$ ( $p<0.0088$; Figs. $3 b$, $5 a)$ and in $\mathrm{MEP}_{\max }$ area by $11.7 \%$ compared with baseline $(p<0.0092$; Figs. $4 b$, $5 a)$. These changes were, however, not significant after correction for multiple comparisons.

Experiment 3: nonspecific stimulation This condition resulted in a significant decrease in $\mathrm{MEP}_{\max }$ by $15.3 \%$ compared with baseline $(p<0.0001$; Figs. $3 c, 4 a)$, but there was no significant change in the $\mathrm{MEP}_{\text {max area }}$ (Figs. 4c, 5a).

Influence of EMG and stimulation dose The average number of cortical stimuli applied per subject was $423.1 \pm 87.2$, $505.8 \pm 51.2$, and $379.6 \pm 51.2$ for the synchronous, delayed, and nonspecific conditions, respectively. The average ERD-related duration of peripheral stimulation per run was $11.5 \pm 2.75 \mathrm{~s}$ and $16.7 \pm 3.98 \mathrm{~s}$ for the synchronous and delayed conditions, respectively. The mean EMG background activity was $47.5 \pm 7.3,34.1 \pm 8.5$, and a

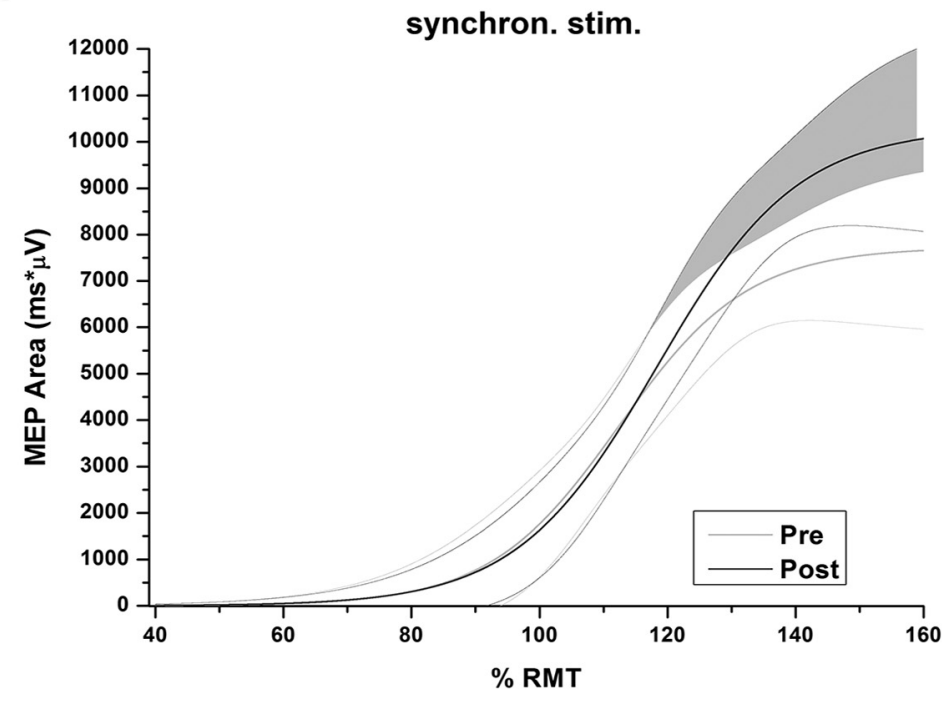

b

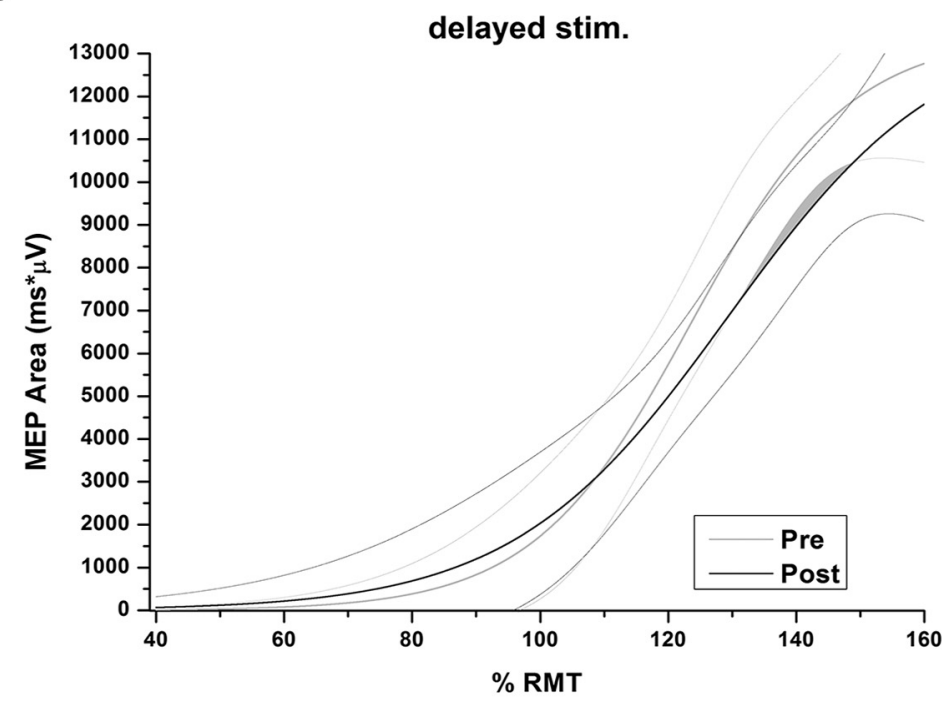

C

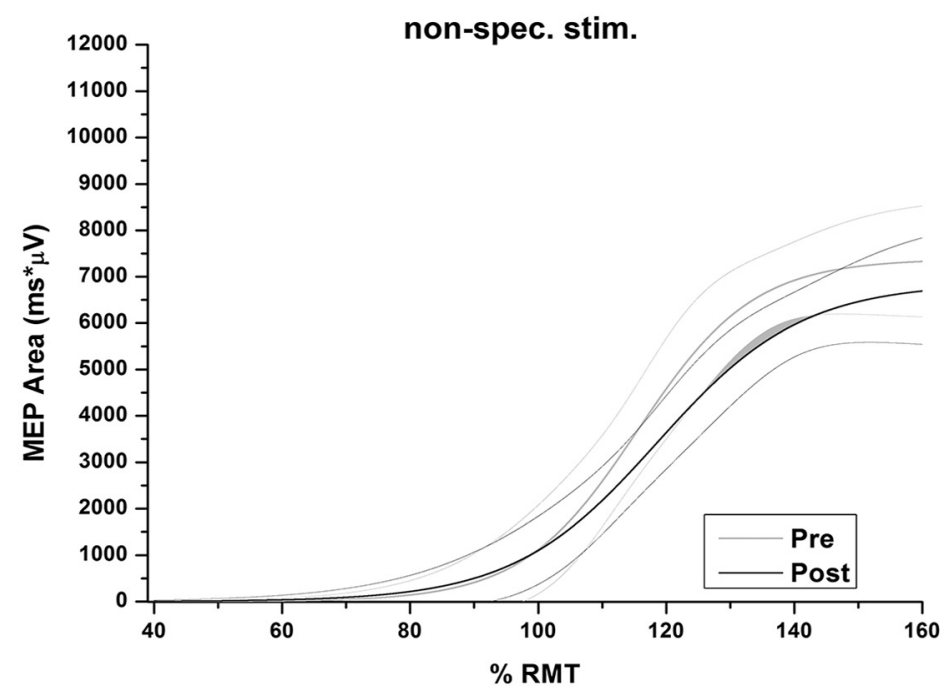

Figure 4. Area under the MEP curve. Boltzmann fit (lines) of the area under the MEP curve (in $\mu \mathrm{V} \times \mathrm{ms}$ ) for pre-intervention (gray) and post-intervention (black). Arrangement $(a, b, c)$ and conventions are otherwise the same as in Figure 2 . 


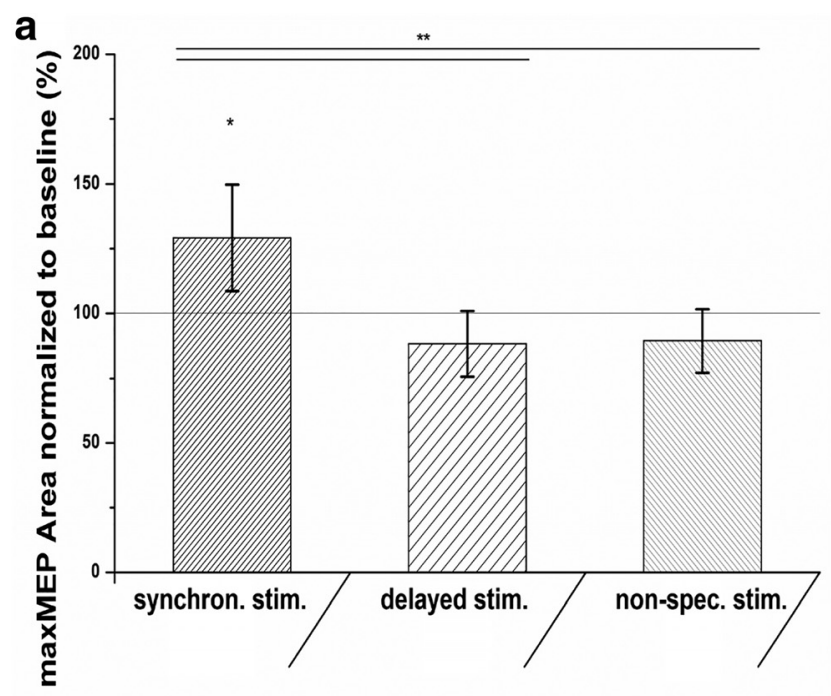

b

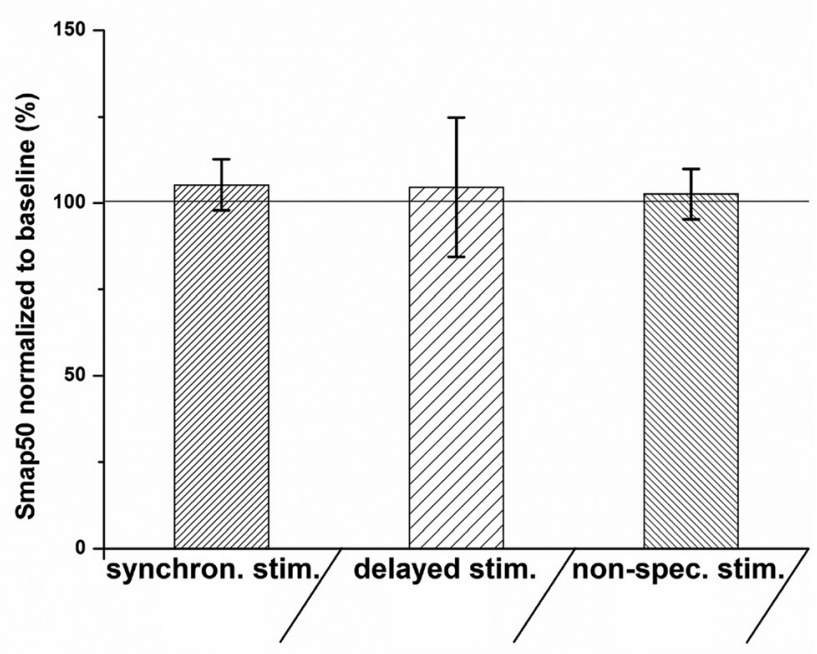

C

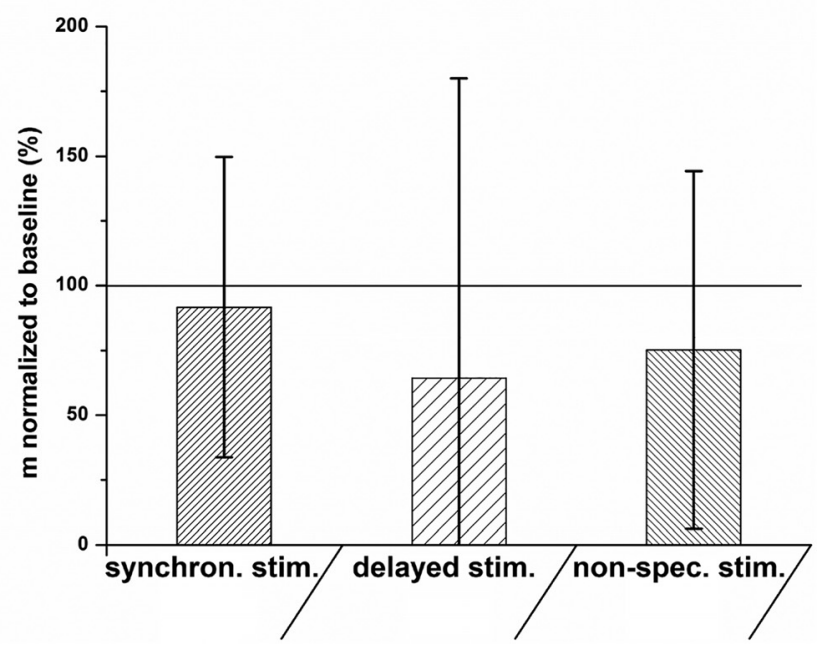

Figure 5. Boltzmann parameters of the area under the MEP curve. Means of ( $\boldsymbol{a}) \mathrm{MEP}_{\text {max area }}$ (b) $S_{\text {area }} 50$, and (c) slope $m$ post-intervention normalized to baseline (in percentage). Arrangement and conventions are otherwise the same as in Figure 3.
$10.7 \pm 4.5 \mu \mathrm{V}$ for the synchronous, delayed, and nonspecific conditions, respectively.

Multiple one-way rmANOVAs with the between-subject effect of intervention and the within-subject variables EMG, ERD duration and number of stimuli revealed significant differences in EMG activity $\left(F_{(2,32)}=6.33 ; p=0.0048\right)$, duration of peripheral stimulation $\left(F_{(1,23)}=11.9 ; p=0.002\right)$, and number of cortical stimuli $\left(F_{(2,32)}=10.3 ; p=0.0004\right)$. Post hoc two-sample $t$ test revealed a significantly lower EMG activity for nonspecific than for synchronous $(t=2.841 ; p=0.01)$, longer duration for delayed than for synchronous $(t=3.45 ; p=0.002)$, and lower number of stimuli for nonspecific than for delayed conditions $(t=2.85 ; p=0.009)$. Multiple partial correlations did not, however, reveal any linear relationship between EMG activity, duration of peripheral stimulation, or number of cortical stimuli and the increase in individual $\mathrm{MEP}_{\text {max }}$ values (all $p$ values $<0.47$, all $p$ values $>0.16$ ).

\section{Discussion}

We investigated a novel BMI protocol with synchronous stimulation where sensorimotor $\beta$-band ERD during kinesthetic MI led to passive hand opening by a robotic orthosis. When this proprioceptive stimulation was paired with concurrent TMS (i.e., synchronous stimulation) of the motor cortex, associative plasticity of the corticospinal projection occurred. In particular, CSE of the motor hand knob area increased at the plateau of the SRC $\left(\mathrm{MEP}_{\max }\right)$, thereby reflecting an increase in the net corticospinal output. The concurrent increase in $\mathrm{MEP}_{\max }$ area suggests this effect to be mediated via the recruitment of additional corticospinal neurons (see below).

Similar to other PAS interventions we observed rapid development, associativity (with $\beta$-ERD), and sustainability of CSE increases after the intervention period (Stefan et al., 2000, 2004; Ziemann et al., 2004; Quartarone et al., 2006). In alignment with other PAS studies, RMT was not altered (Stefan et al., 2000; Koganemaru et al., 2009; Thabit et al., 2010) indicating that no changes occurred at the resting membrane potential of corticospinal neurons (Ziemann et al., 1996). Although changes on the spinal level have not been ruled out, other PAS studies have consistently demonstrated that excitability changes of the spinal alpha-motor neuron do not occur after PAS interventions (Stefan et al., 2000; Wolters et al., 2003; Mrachacz-Kersting et al., 2012).

Two control conditions revealed the brain state-dependency of this PAS protocol. When the TMS pattern used in Experiment 1 (synchronous stimulation) was applied concurrently to proprioceptive stimulation, but without a MI task and independent of $\beta$-band ERD, a significant decrease of CSE occurred (Experiment 3: nonspecific stimulation). When TMS was applied during the MI task, but at a different brain state than in Experiment 1, i.e., whenever the predefined $\beta$-ERD level was not sustained, no CSE changes ensued (Experiment 2: delayed stimulation). These findings indicate that CSE increases did not occur merely on account of the pairing of cortical and peripheral stimulation or the elevated attention during the MI task, and were not mediated solely by a priming effect due to MI itself (Ziemann and Siebner, 2008).

There was, however, a relevant difference between the SRCs of the two control conditions, i.e., decreased (nonspecific stimulation) versus unchanged CSE (delayed stimulation), an observation that is probably attributable to the MI task: single-pulse TMS alone led to decreased CSE in accordance with previous standard low-frequency TMS protocols (Di Lazzaro et al., 2008b) or traditional inhibiting PAS protocols (Di Lazzaro et al., 2009). The 
additional proprioceptive input in the present study did not reverse this CSE reduction (nonspecific condition), a finding in line with previous work on concurrent passive movement and TMS (Edwards et al., 2014). By contrast, the MI task alleviated the CSE decreasing effect of single-pulse TMS so that no pre-/postchanges of the SRC occurred in this condition. This observation was to be expected since cognitive factors such as attention (Stefan et al., 2004) and MI (Royter and Gharabaghi, 2016) have been shown previously to influence PAS effects. Specifically, kinesthetic MI was shown to activate partially the same neuronal populations as motor execution (Pfurtscheller and Neuper, 1997; Lotze et al., 1999; Neuper et al., 2005; Kaiser et al., 2011). MI is also known to increase CSE (Ridding and Rothwell, 1999; Stinear and Byblow, 2004; Stinear et al., 2006; Roosink and Zijdewind, 2010) and to decrease, in accordance with a gating mechanism, short intracortical inhibition (Abbruzzese et al., 1999; Takemi et al., 2013), which could be decreased further by pairing MI with afferent input (Ridding and Rothwell, 1999). This decrease of intracortical inhibition, in turn, was shown to enhance the excitability of $\alpha$-motor neurons, i.e., CSE (Devanne et al., 2002; KouchtirDevanne et al., 2012). Although the exact mechanisms still require clarification, the current approach probably stimulates corticocortical connections to pyramidal neurons during depolarization (Gharabaghi et al., 2014a; Kraus et al., 2016a) by using ERD and proprioceptive stimulation as synergistic input for cortical stimulation. This implies for the potential mechanisms of the investigated PAS intervention: The observed plasticity induction could be mediated by either classical pre-postsynaptic stimulation (Hebb, 1949) or by convergence of two or more presynaptic signals onto a common postsynaptic target, i.e., corticospinal motor neurons in layer V of the motor cortex (Harel and Carmel, 2016). Either way, this protocol amplifies synaptic transmission and triggers plasticity through associative pairing of different stimuli (Di Lazzaro et al., 1998a,b, 2008a,c, 2012).

\section{Neurophysiological considerations}

The CSE changes observed in this pairing study of cortical and proprioceptive stimulation differed relevantly from those in previous paradigms using either proprioceptive (Kraus et al., 2016b) or cortical stimulation (Kraus et al., 2016a), despite the fact that all of these interventions were performed using the very same MI-related and $\beta$-ERD-triggered stimulation paradigm. Separate application of either one of these stimulation techniques resulted in CSE increases in the steep part of the SRC only, thereby indicating a gain increase of the activated corticospinal pathways (Devanne et al., 1997). Moreover, proprioceptive stimulation (Kraus et al., 2016b) and cortical stimulation independent of the brain-state (Kraus et al., 2016a) also resulted in a decrease in the SRC plateau. The novel BMI protocol with synchronous stimulation of the present study inverted this pattern, resulting in an increase of the SRC plateau.

The precise mechanism regarding activated neurons and involved pathways is uncertain because this study was performed noninvasively on intact human subjects. However, factors such as elevated background muscle activity (Devanne et al., 1997), higher gain (Devanne et al., 1997) or trans-synaptic excitability of the corticospinal pathway during movement (Ridding and Rothwell, 1997) can be excluded, since the SRCs were acquired at rest. Moreover, repetitive discharges of motor neurons could not explain our findings either, because such phenomena had been reported during additional voluntary pre-activation of the muscle only (Z'Graggen et al., 2005).
In this context, the modification of the MEP shape after the intervention helps to better characterize the induced plasticity: CSE enhancements can be mediated by pure rises of the MEP peak-to-peak amplitude or by concurrent increases of the area under the MEP curve. The latter cannot be explained by improved synapse efficiency of the already activated neurons, which would lead to higher MEP peak-to-peak amplitudes, and requires therefore the involvement of additional neurons (Magistris et al., 1998; Rösler et al., 2008). This phenomenon occurred, moreover, at the SRC saturation level that reflects an increased net corticospinal output. Together, these findings suggest the additional recruitment of higher threshold corticospinal neurons as the most plausible explanation for the results (Di Lazzaro et al., 1998a,b, 2008c, 2012).

\section{Methodological considerations}

However, some open questions need to be addressed in future studies with additional and/or alternative control conditions: The effects of delayed stimulation on CSE might be increased, should a more optimal timing of cortical stimulation after offset of the robotic hand opening be detected in relation to the peak of the proprioceptive-related evoked potential (Bötzel et al., 1997; Seiss et al., 2002). Previous work suggests, furthermore, that the somatosensory, but not the motor cortex is sufficiently modulated by the proprioceptive input of the robotic orthosis (Kraus et al., 2016b), i.e., resembling the changes induced by sensory stimulation below motor threshold (Chipchase et al., 2011; Schabrun et al., 2012; Saito et al., 2013; Shitara et al., 2013). Future work may therefore explore afferent input above the motor threshold by peripheral stimulation that induces a tonic muscle contraction, e.g., by functional electrical stimulation (FES). In fact, previous work suggests an additive effect of concurrent MI and FES on ERD (Reynolds et al., 2015), and the modulation of a FESTMS based PAS protocol by MI-related $\beta$-ERD (Royter and Gharabaghi, 2016).

The control conditions of this study were designed with a specific neurorehabilitation goal in mind; the restoration of finger extension in stroke patients with hand paralysis. Future studies may explore cortical stimulation during finger flexion or various other movements and also better delineate the interactions of muscle agonists and antagonists on CSE (Massie et al., 2015), e.g., by using refined TMS mapping techniques (Mathew et al., 2016). To validate the brain state-dependency of the present PAS effects, future studies may also include ERS-related TMS as a control condition. On the basis of the present findings, we speculate that such an intervention would show a decrease of CSE. In line with previous observations regarding brain state-dependent TMS (Kraus et al., 2016a), $\beta$-ERD was demonstrated as an appropriate marker to trigger state-dependent TMS that aims to increase CSE. These findings are in accordance with previous studies which showed an inverse correlation of CSE with $\beta$-band power (Schulz et al., 2014; Kraus et al., 2016b). However, to confirm the frequency-specificity of these effects in the context of neurophysiologically informed interventions (Romei et al., 2016), other frequency bands such as the $\alpha$-band, a correlate of gating information by inhibiting task-irrelevant regions, should also be explored (Jensen and Mazaheri, 2010).

In conclusion, recruitment of additional corticospinal neurons may be achieved with a BMI protocol with synchronous cortical stimulation. These findings resemble a gating mechanism and are potentially important for the restoration of motor function following lesions of the corticospinal tract with hand paralysis. 


\section{References}

Abbruzzese G, Assini A, Buccolieri A, Marchese R, Trompetto C (1999) Changes of intracortical inhibition during motor imagery in human subjects. Neurosci Lett 263:113-116. CrossRef Medline

Altman DG, Bland JM (2011) How to obtain the $P$ value from a confidence interval. BMJ 343:d2304. CrossRef Medline

Arai K, Lok J, Guo S, Hayakawa K, Xing C, Lo EH (2011) Cellular mechanisms of neurovascular damage and repair after stroke. J Child Neurol 26:1193-1198. CrossRef Medline

Bauer R, Gharabaghi A (2017) Constraints and adaptation of closed-loop neuroprosthetics for functional restoration. Front Neurosci 11:111. CrossRef Medline

Bauer R, Fels M, Vukelić M, Ziemann U, Gharabaghi A (2015) Bridging the gap between motor imagery and motor execution with a brain-robot interface. Neuroimage 108:319-327. CrossRef Medline

Bauer R, Vukelić M, Gharabaghi A (2016a) What is the optimal task difficulty for reinforcement learning of brain self-regulation? Clin Neurophysiol 127:3033-3041. CrossRef Medline

Bauer R, Fels M, Royter V, Raco V, Gharabaghi A (2016b) Closed-loop adaptation of neurofeedback based on mental effort facilitates reinforcement learning of brain self-regulation. Clin Neurophysiol 127:3156-3164. CrossRef Medline

Bauer R, Gharabaghi A (2015a) Estimating cognitive load during selfregulation of brain activity and neurofeedback with therapeutic braincomputer interfaces. Front Behav Neurosci 9:21. CrossRef Medline

Bauer R, Gharabaghi A (2015b) Reinforcement learning for adaptive threshold control of restorative brain-computer interfaces: a Bayesian simulation. Front Neurosci 9:36. CrossRef Medline

Belardinelli P, Laer L, Ortiz E, Braun C, Gharabaghi A (2017) Plasticity of premotor cortico-muscular coherence in severely impaired stroke patients with hand paralysis. Neuroimage Clin 14:726-733. CrossRef Medline

Bötzel K, Ecker C, Schulze S (1997) Topography and dipole analysis of reafferent electrical brain activity following the Bereitschaftspotential. Exp Brain Res 114:352-361. CrossRef Medline

Brauchle D, Vukelić M, Bauer R, Gharabaghi A (2015) Brain state-dependent robotic reaching movement with a multi-joint arm exoskeleton. Combining brain-machine interfacing and robotic rehabilitation. Front Hum Neurosci 9:564. CrossRef Medline

Buch ER, Johnen VM, Nelissen N, O'Shea J, Rushworth MF (2011) Noninvasive associative plasticity induction in a corticocortical pathway of the human brain. J Neurosci 31:17669-17679. CrossRef Medline

Bunday KL, Perez MA (2012) Motor recovery after spinal cord injury enhanced by strengthening corticospinal synaptic transmission. Curr Biol 22:2355-2361. CrossRef Medline

Bütefisch CM, Khurana V, Kopylev L, Cohen LG (2004) Enhancing encoding of a motor memory in the primary motor cortex by cortical stimulation. J Neurophysiol 91:2110-2116. CrossRef Medline

Chen R, Yaseen Z, Cohen LG, Hallett M (1998) Time course of corticospinal excitability in reaction time and self-paced movements. Ann Neurol 44: 317-325. CrossRef Medline

Chipchase LS, Schabrun SM, Hodges PW (2011) Corticospinal excitability is dependent on the parameters of peripheral electric stimulation: a preliminary study. Arch Phys Med Rehabil 92:1423-1430. CrossRef Medline

Danner N, Julkunen P, Könönen M, Säisänen L, Nurkkala J, Karhu J (2008) Navigated transcranial magnetic stimulation and computed electric field strength reduce stimulator-dependent differences in the motor threshold. J Neurosci Methods 174:116-122. CrossRef Medline

Danner N, Könönen M, Säisänen L, Laitinen R, Mervaala E, Julkunen P (2012) Effect of individual anatomy on resting motor threshold-computed electric field as a measure of cortical excitability. J Neurosci Methods 203: 298-304. CrossRef Medline

Darvishi S, Gharabaghi A, Boulay CB, Ridding MC, Abbott D, Baumert M (2017) Proprioceptive feedback facilitates motor imagery-related operant learning of sensorimotor $\beta$-band modulation. Front Neurosci 11:60. CrossRef Medline

Davare M, Montague K, Olivier E, Rothwell JC, Lemon RN (2009) Ventral premotor to primary motor cortical interactions during object-driven grasp in humans. Cortex 45:1050-1057. CrossRef Medline

Devanne H, Lavoie BA, Capaday C (1997) Input-output properties and gain changes in the human corticospinal pathway. Exp Brain Res 114: 329-338. CrossRef Medline

Devanne H, Cohen LG, Kouchtir-Devanne N, Capaday C (2002) Integrated motor cortical control of task-related muscles during pointing in humans. J Neurophysiol 87:3006-3017. CrossRef Medline

Di Lazzaro V, Oliviero A, Profice P, Saturno E, Pilato F, Insola A, Mazzone P, Tonali P, Rothwell JC (1998a) Comparison of descending volleys evoked by transcranial magnetic and electric stimulation in conscious humans. Electroencephalogr Clin Neurophysiol 109:397-401. CrossRef Medline

Di Lazzaro V, Restuccia D, Oliviero A, Profice P, Ferrara L, Insola A, Mazzone P, Tonali P, Rothwell JC (1998b) Effects of voluntary contraction on descending volleys evoked by transcranial stimulation in conscious humans. J Physiol 508:625-633. CrossRef Medline

Di Lazzaro V, Pilato F, Dileone M, Profice P, Oliviero A, Mazzone P, Insola A, Ranieri F, Meglio M, Tonali PA, Rothwell JC (2008a) The physiological basis of the effects of intermittent theta burst stimulation of the human motor cortex. J Physiol 586:3871-3879. CrossRef Medline

Di Lazzaro V, Pilato F, Dileone M, Profice P, Oliviero A, Mazzone P, Insola A, Ranieri F, Tonali PA, Rothwell JC (2008b) Low-frequency repetitive transcranial magnetic stimulation suppresses specific excitatory circuits in the human motor cortex. J Physiol 586:4481-4487. CrossRef Medline

Di Lazzaro V, Ziemann U, Lemon RN (2008c) State of the art: physiology of transcranial motor cortex stimulation. Brain Stimul 1:345-362. CrossRef Medline

Di Lazzaro V, Dileone M, Profice P, Pilato F, Oliviero A, Mazzone P, Di Iorio R, Capone F, Ranieri F, Florio L, Tonali PA (2009) LTD-like plasticity induced by paired associative stimulation: direct evidence in humans. Exp Brain Res 194:661-664. CrossRef Medline

Di Lazzaro V, Profice P, Ranieri F, Capone F, Dileone M, Oliviero A, Pilato F (2012) I-wave origin and modulation. Brain Stimul 5:512-525. CrossRef Medline

Edwards DJ, Dipietro L, Demirtas-Tatlidede A, Medeiros AH, Thickbroom GW, Mastaglia FL, Krebs HI, Pascual-Leone A (2014) Movement-generated afference paired with transcranial magnetic stimulation: an associative stimulation paradigm. J Neuroeng Rehabil 11:31. CrossRef Medline

Edwardson MA, Lucas TH, Carey JR, Fetz EE (2013) New modalities of brain stimulation for stroke rehabilitation. Exp Brain Res 224:335-358. CrossRef Medline

Espenhahn S, de Berker AO, van Wijk BC, Rossiter HE, Ward NS (2017) Movement-related beta oscillations show high intra-individual reliability. Neuroimage 147:175-185. CrossRef Medline

Gharabaghi A (2015) Activity-dependent brain stimulation and robotassisted movements for use-dependent plasticity. Clin Neurophysiol 126: 853-854. CrossRef Medline

Gharabaghi A (2016) What turns assistive into restorative brain-machine interfaces? Front Neurosci 10:456. CrossRef Medline

Gharabaghi A, Kraus D, Leão MT, Spüler M, Walter A, Bogdan M, Rosenstiel W, Naros G, Ziemann U (2014a) Coupling brain-machine interfaces with cortical stimulation for brain-state dependent stimulation: enhancing motor cortex excitability for neurorehabilitation. Front Hum Neurosci 8:122. CrossRef Medline

Gharabaghi A, Naros G, Khademi F, Jesser J, Spüler M, Walter A, Bogdan M, Rosenstiel W, Birbaumer N (2014b) Learned self-regulation of the lesioned brain with epidural electrocorticography. Front Behav Neurosci 8:429. CrossRef Medline

Goldsworthy MR, Müller-Dahlhaus F, Ridding MC, Ziemann U (2015) Resistant against de-depression: LTD-like plasticity in the human motor cortex induced by spaced cTBS. Cereb Cortex 25:1724-1734. CrossRef Medline

Gomez-Rodriguez M, Peters J, Hill J, Schölkopf B, Gharabaghi A, GrosseWentrup M (2011) Closing the sensorimotor loop: haptic feedback facilitates decoding of motor imagery. J Neural Eng 8:036005. CrossRef Medline

Groppa S, Oliviero A, Eisen A, Quartarone A, Cohen LG, Mall V, Kaelin-Lang A, Mima T, Rossi S, Thickbroom GW, Rossini PM, Ziemann U, Valls-Solé J, Siebner HR (2012) A practical guide to diagnostic transcranial magnetic stimulation: report of an IFCN committee. Clin Neurophysiol 123: 858-882. CrossRef Medline

Harel NY, Carmel JB (2016) Paired stimulation to promote lasting augmentation of corticospinal circuits. Neural Plast 2016:7043767. CrossRef Medline

Hebb, D. O (1949) The organization of behavior: a neuropsychological approach. New York, NY: Wiley.

Houdayer E, Degardin A, Cassim F, Bocquillon P, Derambure P, Devanne H (2008) The effects of low- and high-frequency repetitive TMS on the 
input/output properties of the human corticospinal pathway. Exp Brain Res 187:207-217. CrossRef Medline

Huber P, Winkler R (1981) Die rolle der computertomographischen gehirnuntersuchung bei epilepsiekranken. Schweiz Rundsch Med Prax 70: 1553-1557. Medline

Jackson A, Mavoori J, Fetz EE (2006) Long-term motor cortex plasticity induced by an electronic neural implant. Nature 444:56-60. CrossRef Medline

Jensen O, Mazaheri A (2010) Shaping functional architecture by oscillatory alpha activity: gating by inhibition. Front Hum Neurosci 4:186. CrossRef Medline

Kaiser V, Kreilinger A, Müller-Putz GR, Neuper C (2011) First steps toward a motor imagery based stroke BCI: new strategy to set up a classifier. Front Neurosci 5:86. CrossRef Medline

Koganemaru S, Mima T, Nakatsuka M, Ueki Y, Fukuyama H, Domen K (2009) Human motor associative plasticity induced by paired bihemispheric stimulation. J Physiol 587:4629-4644. CrossRef Medline

Kouchtir-Devanne N, Capaday C, Cassim F, Derambure P, Devanne H (2012) Task-dependent changes of motor cortical network excitability during precision grip compared with isolated finger contraction. J Neurophysiol 107:1522-1529. CrossRef Medline

Kraus D, Gharabaghi A (2015) Projecting navigated TMS sites on the gyral anatomy decreases inter-subject variability of cortical motor maps. Brain Stimul 8:831-837. CrossRef Medline

Kraus D, Gharabaghi A (2016) Neuromuscular plasticity: disentangling stable and variable motor maps in the human sensorimotor cortex. Neural Plast 2016:7365609. CrossRef Medline

Kraus D, Boyle V, Leibig N, Stark GB, Penna V (2015) The neuro-spheroid: a novel 3D in vitro model for peripheral nerve regeneration. J Neurosci Methods 246:97-105. CrossRef Medline

Kraus D, Naros G, Bauer R, Khademi F, Leão MT, Ziemann U, Gharabaghi A (2016a) Brain state-dependent transcranial magnetic closed-loop stimulation controlled by sensorimotor desynchronization induces robust increase of corticospinal excitability. Brain Stimul 9:415-424. CrossRef Medline

Kraus D, Naros G, Bauer R, Leão MT, Ziemann U, Gharabaghi A (2016b) Brain-robot interface driven plasticity: distributed modulation of corticospinal excitability. Neuroimage 125:522-532. CrossRef Medline

Lotze M, Montoya P, Erb M, Hülsmann E, Flor H, Klose U, Birbaumer N, Grodd W (1999) Activation of cortical and cerebellar motor areas during executed and imagined hand movements: an fMRI study. J Cogn Neurosci 11:491-501. CrossRef Medline

Lucas TH, Fetz EE (2013) Myo-cortical crossed feedback reorganizes primate motor cortex output. J Neurosci 33:5261-5274. CrossRef Medline

Magistris MR, Rösler KM, Truffert A, Myers JP (1998) Transcranial stimulation excites virtually all motor neurons supplying the target muscle: a demonstration and a method improving the study of motor evoked potentials. Brain 121:437-450. CrossRef Medline

Massie CL, Kantak SS, Narayanan P, Wittenberg GF (2015) Timing of motor cortical stimulation during planar robotic training differentially impacts neuroplasticity in older adults. Clin Neurophysiol 126:1024-1032. CrossRef Medline

Mathew J, Kübler A, Bauer R, Gharabaghi A (2016) Probing corticospinal recruitment patterns and functional synergies with transcranial magnetic stimulation. Front Cell Neurosci 10:175. CrossRef Medline

McFarland DJ, Wolpaw JR (2008) Sensorimotor rhythm-based braincomputer interface (BCI): model order selection for autoregressive spectral analysis. J Neural Eng 5:155-162. CrossRef Medline

McFarland DJ, Miner LA, Vaughan TM, Wolpaw JR (2000) Mu and beta rhythm topographies during motor imagery and actual movements. Brain Topogr 12:177-186. CrossRef Medline

Möller C, Arai N, Lücke J, Ziemann U (2009) Hysteresis effects on the input-output curve of motor evoked potentials. Clin Neurophysiol 120: 1003-1008. CrossRef Medline

Mrachacz-Kersting N, Kristensen SR, Niazi IK, Farina D (2012) Precise temporal association between cortical potentials evoked by motor imagination and afference induces cortical plasticity. J Physiol 590:1669-1682. CrossRef Medline

Naros G, Gharabaghi A (2015) Reinforcement learning of self-regulated $\beta$-oscillations for motor restoration in chronic stroke. Front Hum Neurosci 9:391. CrossRef Medline

Naros G, Naros I, Grimm F, Ziemann U, Gharabaghi A (2016) Reinforce- ment learning of self-regulated sensorimotor $\beta$-oscillations improves motor performance. Neuroimage 134:142-152. CrossRef Medline

Neuper C, Scherer R, Reiner M, Pfurtscheller G (2005) Imagery of motor actions: differential effects of kinesthetic and visual-motor mode of imagery in single-trial EEG. Brain Res Cogn Brain Res 25:668-677. CrossRef Medline

Oldfield RC (1971) The assessment and analysis of handedness: the Edinburgh inventory. Neuropsychologia 9:97-113. CrossRef Medline

Pfurtscheller G, Neuper C (1997) Motor imagery activates primary sensorimotor area in humans. Neurosci Lett 239:65-68. CrossRef Medline

Quartarone A, Rizzo V, Bagnato S, Morgante F, Sant'Angelo A, Girlanda P, Siebner HR (2006) Rapid-rate paired associative stimulation of the median nerve and motor cortex can produce long-lasting changes in motor cortical excitability in humans. J Physiol 575:657-670. CrossRef Medline

Raco V, Bauer R, Tharsan S, Gharabaghi A (2016) Combining TMS and tACS for closed-loop phase-dependent modulation of corticospinal excitability: a feasibility study. Front Cell Neurosci 10:143. CrossRef Medline

Reynolds C, Osuagwu BA, Vuckovic A (2015) Influence of motor imagination on cortical activation during functional electrical stimulation. Clin Neurophysiol 126:1360-1369. CrossRef Medline

Ridding MC, Rothwell JC (1997) Stimulus/response curves as a method of measuring motor cortical excitability in man. Electroencephalogr Clin Neurophysiol 105:340-344. CrossRef Medline

Ridding MC, Rothwell JC (1999) Afferent input and cortical organisation: a study with magnetic stimulation. Exp Brain Res 126:536-544. CrossRef Medline

Rizzo V, Siebner HS, Morgante F, Mastroeni C, Girlanda P, Quartarone A (2009) Paired associative stimulation of left and right human motor cortex shapes interhemispheric motor inhibition based on a Hebbian mechanism. Cereb Cortex 19:907-915. CrossRef Medline

Romei V, Thut G, Silvanto J (2016) Information-based approaches of noninvasive transcranial brain stimulation. Trends Neurosci 39:782-795. CrossRef Medline

Roosink M, Zijdewind I (2010) Corticospinal excitability during observation and imagery of simple and complex hand tasks: implications for motor rehabilitation. Behav Brain Res 213:35-41. CrossRef Medline

Rösler KM, Roth DM, Magistris MR (2008) Trial-to-trial size variability of motor-evoked potentials: a study using the triple stimulation technique. Exp Brain Res 187:51-59. CrossRef Medline

Rossi S, Hallett M, Rossini PM, Pascual-Leone A (2009) Safety, ethical considerations, and application guidelines for the use of transcranial magnetic stimulation in clinical practice and research. Clin Neurophysiol 120:2008-2039. CrossRef Medline

Rossiter HE, Boudrias MH, Ward NS (2014) Do movement-related beta oscillations change after stroke? J Neurophysiol 112:2053-2058. CrossRef Medline

Royter V, Gharabaghi A (2016) Brain state-dependent closed-loop modulation of paired associative stimulation controlled by sensorimotor desynchronization. Front Cell Neurosci 10:115. CrossRef Medline

Saito K, Yamaguchi T, Yoshida N, Tanabe S, Kondo K, Sugawara K (2013) Combined effect of motor imagery and peripheral nerve electrical stimulation on the motor cortex. Exp Brain Res 227:333-342. CrossRef Medline

Schabrun SM, Ridding MC, Galea MP, Hodges PW, Chipchase LS (2012) Primary sensory and motor cortex excitability are co-modulated in response to peripheral electrical nerve stimulation. PloS One 7:e51298. CrossRef Medline

Schalk G, McFarland DJ, Hinterberger T, Birbaumer N, Wolpaw JR (2004) BCI2000: a general-purpose brain-computer interface (BCI) system. IEEE Trans Biomed Eng 51:1034-1043. CrossRef Medline

Schulz H, Ubelacker T, Keil J, Müller N, Weisz N (2014) Now I am readynow I am not: the influence of pre-TMS oscillations and corticomuscular coherence on motor-evoked potentials. Cereb Cortex 24:1708-1719. CrossRef Medline

Seiss E, Hesse CW, Drane S, Oostenveld R, Wing AM, Praamstra P (2002) Proprioception-related evoked potentials: origin and sensitivity to movement parameters. Neuroimage 17:461-468. CrossRef Medline

Shitara H, Shinozaki T, Takagishi K, Honda M, Hanakawa T (2013) Movement and afferent representations in human motor areas: a simultaneous neuroimaging and transcranial magnetic/peripheral nerve-stimulation study. Front Hum Neurosci 7:554. CrossRef Medline

Stefan K, Kunesch E, Cohen LG, Benecke R, Classen J (2000) Induction of 
plasticity in the human motor cortex by paired associative stimulation. Brain 123:572-584. CrossRef Medline

Stefan K, Wycislo M, Classen J (2004) Modulation of associative human motor cortical plasticity by attention. J Neurophysiol 92:66-72. CrossRef Medline

Stinear CM, Byblow WD (2004) Modulation of corticospinal excitability and intracortical inhibition during motor imagery is task-dependent. Exp Brain Res 157:351-358. CrossRef Medline

Stinear CM, Byblow WD, Steyvers M, Levin O, Swinnen SP (2006) Kinesthetic, but not visual, motor imagery modulates corticomotor excitability. Exp Brain Res 168:157-164. CrossRef Medline

Takemi M, Masakado Y, Liu M, Ushiba J (2013) Event-related desynchronization reflects downregulation of intracortical inhibition in human primary motor cortex. J Neurophysiol 110:1158-1166. CrossRef Medline

Taylor JL, Martin PG (2009) Voluntary motor output is altered by spiketiming-dependent changes in the human corticospinal pathway. J Neurosci 29:11708-11716. CrossRef Medline

Thabit MN, Ueki Y, Koganemaru S, Fawi G, Fukuyama H, Mima T (2010) Movement-related cortical stimulation can induce human motor plasticity. J Neurosci 30:11529-11536. CrossRef Medline

Todd G, Rogasch NC, Flavel SC, Ridding MC (2009) Voluntary movement and repetitive transcranial magnetic stimulation over human motor cortex. J Appl Physiol 106:1593-1603. CrossRef Medline

Touge T, Gerschlager W, Brown P, Rothwell JC (2001) Are the after-effects of low-frequency rTMS on motor cortex excitability due to changes in the efficacy of cortical synapses? Clin Neurophysiol 112:2138-2145. CrossRef Medline

Vukelić M, Gharabaghi A (2015a) Oscillatory entrainment of the motor cortical network during motor imagery is modulated by the feedback modality. Neuroimage 111:1-11. CrossRef Medline

Vukelić M, Gharabaghi A (2015b) Self-regulation of circumscribed brain activity modulates spatially selective and frequency specific connectivity of distributed resting state networks. Front Behav Neurosci 9:181. CrossRef Medline

Vukelić M, Bauer R, Naros G, Naros I, Braun C, Gharabaghi A (2014) Lateralized alpha-band cortical networks regulate volitional modulation of beta-band sensorimotor oscillations. Neuroimage 87:147-153. CrossRef Medline

Walter A, Ramos Murguialday A, Spüler M, Naros G, Leão MT, Gharabaghi A, Rosenstiel W, Birbaumer N, Bogdan M (2012) Coupling BCI and cortical stimulation for brain-state-dependent stimulation: methods for spectral estimation in the presence of stimulation after-effects. Front Neural Circuits 6:87. CrossRef Medline

Wolters A, Sandbrink F, Schlottmann A, Kunesch E, Stefan K, Cohen LG, Benecke R, Classen J (2003) A temporally asymmetric Hebbian rule governing plasticity in the human motor cortex. J Neurophysiol 89:2339_ 2345. CrossRef Medline

Xu R, Jiang N, Mrachacz-Kersting N, Lin C, Asín Prieto G, Moreno JC, Pons JL, Dremstrup K, Farina D (2014) A closed-loop brain-computer interface triggering an active ankle-foot orthosis for inducing cortical neural plasticity. IEEE Trans Biomed Eng 61:2092-2101. CrossRef Medline

Z'Graggen WJ, Humm AM, Durisch N, Magistris MR, Rösler KM (2005) Repetitive spinal motor neuron discharges following single transcranial magnetic stimuli: a quantitative study. Clin Neurophysiol 116:16281637. CrossRef Medline

Ziemann U, Siebner HR (2008) Modifying motor learning through gating and homeostatic metaplasticity. Brain Stimul 1:60-66. CrossRef Medline

Ziemann U, Lönnecker S, Steinhoff BJ, Paulus W (1996) Effects of antiepileptic drugs on motor cortex excitability in humans: a transcranial magnetic stimulation study. Ann Neurol 40:367-378. CrossRef Medline

Ziemann U, Ilić TV, Iliać TV, Pauli C, Meintzschel F, Ruge D (2004) Learning modifies subsequent induction of long-term potentiation-like and long-term depression-like plasticity in human motor cortex. J Neurosci 24:1666-1672. CrossRef Medline 